\title{
Association between atherogenic index of plasma and left ventricular hypertrophy in patients with chronic heart failure with mid- range ejection fraction
}

\author{
Povezanost aterogenog indeksa plazme i hipertrofije lijeve klijetke $u$ \\ bolesnika sa zatajivanjem srca s ejekcijskom frakcijom srednjeg raspona
}

\author{
Asparuh Nikolovi", Maria Tzekova², Konstantin Kostov², Ana Kostadinovska², Svetla Blazheva ${ }^{3}$
}

\begin{abstract}
Aim: The aim of the present study was to investigate whether an association between lipid indices- atherogenic index of plasma (AIP), Castelli Risk Index I (CRI-I), Castelli Risk Index II (CRI-II) and triglyceride index (TGL-index) and the development of left ventricular hypertrophy exists in patients with heart failure with mid-range ejection fraction (HFmrEF). Material and methods: The study involved 56 patients with HFmrEF and normal lipid profile, median age 64 (47-84) and 22 healthy subjects, median age 58 (51-69). The patients were divided in two subgroups: subjects with left ventricular hypertrophy ( $n=32) ;(H F m r E F+L V H)$ and subjects without left ventricular hypertrophy $(n=24)$; (HFmrEF-LVH). The lipid profile was measured by laboratory, while lipid indices were calculated, using the established formulas. Results: There was not statistically significant difference between the lipid indices in patients with heart failure with mid-range ejection fraction compared to healthy controls ( $p>0.05)$. HFmrEF+LVH patients showed statistically significantly higher values of atherogenic index of plasma than HFrEF-LVH patients: $0.16(0.05 \div 0.37)$ vs. $0.04(0.01 \div 0.11) ;(K W=5.80 ; p=0.02)$. $\mathrm{TC} / \mathrm{HDL}, \mathrm{LDL} / \mathrm{HDL}$ and TG/HDL values were not significantly higher in HFmrHEF+LVH than HFmrEF-LVH patients: $4.8(3.98 \div 5.75)$ vs. $4.49(3.58 \div 5.63) ; 2.91(2.1 \div 4.0)$ vs. $2.9(2.5 \div 4.25)$ and $1.36(1.11 \div 2.08)$ vs. $1.13(0.9 \div 1.53)$, respectively $(p>0.05)$. No significant gender differences between lipid indices were found. Atherogenic index of plasma showed correlation with LVH ( $r=0.45 ; p=0.01)$ and interventricular septum thickness $(r=0.55 ; p=0.002)$. Conclusion: Our findings show an association between atherogenic index of plasma and LVH in patients with HFmrEF with normal lipid profile. Further studies are warranted to confirm whether determination of AIP may be used for monitoring development and progression of left ventricular hypertrophy in heart failure with mid-range ejection fraction.
\end{abstract}

Key words: heart failure; hypertrophy, left ventricular; lipids

Sažetak. Cilj: Cilj ove studije bio je istražiti postoji li povezanost između lipidnih indeksa aterogeni indeks plazme (engl. atherogenic index of plasma; AIP), Castellijev indeks rizika I (engl. Castelli Risk Index I; CRI-I), Castellijev indeks rizika II (engl. Castelli Risk Index II; CRI-II) i trigliceridni indeks (engl. triglyceride index; TGL-index), i razvoja hipertrofije lijeve klijetke u bolesnika sa zatajivanjem srca $s$ umjereno smanjenom ejekcijskom frakcijom (HFmrEF). Materijali i metode: Ispitano je 56 bolesnika s HFmrEF s normalnim lipidnim profilom, prosječne dobi $64(47-84)$ godine i 22 zdrava ispitanika prosječne dobi $58(51-69)$. Pacijenti su podijeljeni u dvije podskupine: ispitanici s hipertrofijom lijeve klijetke $(n=32)$ $(\mathrm{HFmrEF}+\mathrm{LVH}) \mathrm{i}$ ispitanici bez hipertrofije lijeve klijetke $(n=24)(\mathrm{HFmrEF}-\mathrm{LVH})$. Profil lipida mjeren je laboratorijski, dok su indeksi lipida izračunati pomoću ustaljenih formula. Rezultati: Nije bilo statistički značajne razlike između indeksa lipida u bolesnika sa srčanim zatajenjem s izbacivačkom frakcijom srednjeg opsega u usporedbi sa zdravim kontrolama ( $p>0,05)$. Pacijenti s HFmrEF+LVH pokazali su statistički značajno veće vrijednosti

\author{
${ }^{1}$ Division of Medicine, Cardiovascular \\ Research Working Group, Institute for \\ Scientific Research, Medical University, \\ Pleven, Bulgaria \\ ${ }^{2}$ Medical University, Pleven, Bulgaria \\ ${ }^{3}$ Department of Clinical laboratory, clinical \\ immunology and allergology, Medical \\ University, Pleven, Bulgaria
}

\author{
*Corresponding author: \\ Assoc. Prof. Asparuh Nikolov M.D., Ph.D. \\ Division of Medicine, Cardiovascular \\ Research Working Group, Institute for \\ Scientific Research, Medical University \\ 1, St. Kliment Ohridski Str., 5800 Pleven, \\ Bulgaria \\ E-mail: a_nicoloff@yahoo.com
}


aterogenog indeksa plazme od bolesnika s HFmrEF-LVH: $0,16(0,05 \div 0,37)$ naspram $0,04(0,01 \div 0,11)(\mathrm{KW}=5,80$; $\mathrm{p}=0,02)$. Vrijednosti TC/HDL, LDL/ HDL i TG/HDL nisu bile statistički značajno više u bolesnika s HFmrEF+LVH nego $u$ skupini HFmrEF-LVH: 4,8 $(3,98 \div 5,75)$ naspram 4,59 $(3,58 \div$ $5,63), 2,91(2,1 \div 4.0)$ naspram $2,9(2,5 \div 4,25)$, odnosno $1,36(1,11 \div 2,08)$ naspram $1,13(0,9 \div 1,53)$ ( $p>0,05)$. Nisu pronađene značajne razlike između indeksa lipida koje bi ovisile o spolu ispitanika. Aterogeni indeks plazme pokazao je korelaciju s LVH $(r=0,45 ; p=0,01)$ i debljinom interventrikularnog septuma $(r=0,55 ; p=0,002)$. Zaključak: Naši nalazi pokazuju povezanost između aterogenog indeksa plazme i LVH u bolesnika s HFrEF s normalnim lipidnim profilom. Daljnja ispitivanja opravdana su kako bi se potvrdilo može li se određivanje AIP koristiti za praćenje razvoja i napredovanja hipertrofije lijeve klijetke u zatajenju srca s izbacivačkom frakcijom srednjeg raspona.

Ključne riječi: hipertrofija lijeve klijetke; lipidi; zatajenje srca

Atherogenic index of plasma values in patients with heart failure with mid-range ejection fraction and left ventricular hypertrophy is statistically significantly higher than in patients without left ventricular hypertrophy. Atherogenic index of plasma correlates with left ventricular hypertrophy in heart failure with mid-range ejection fraction.

\section{INTRODUCTION}

Cardiac remodeling describes the reorganization of myocytes, intercellular matrix components and vessels in response to the index stimuli. Left ventricular hypertrophy (LVH) and fibrosis are major characteristics of myocardial remodeling. These processes increase heart workload and play key roles in cardiovascular morbidity and mortality ${ }^{1}$ Other than age, LVH is the most potent predictor of adverse cardiovascular events in the hypertensive population, and is also an independent risk factor for ischemic heart disease (IHD), sudden cardiac death, heart failure and stroke ${ }^{2}$.

Heart failure with mid-range ejection fraction (HFmrEF) mostly represents a transition phenotype, either to full recovery or to a downhill course of worsening systolic function ${ }^{3,4}$. Despite HFmrEF has a high prevalence of hypertension, atrial fibrillation and vascular disease, limited data is available on the interaction of lipids with left ventricular (LV) morphology in the settings of HFmrEF.
There is growing evidence that a cross-talk exists between the renin-angiotensin system (RAS) and lipoproteins. Studies suggest up-regulation of different RAS components and atherosclerosis. Angiotensin II (AngII) over-activation has been assumed to aggravate atherosclerosis progression. It has been theorized that "lipid accumulation in the blood vessels enhances the expression of RAS components; on the other hand, activation of RAS stimulates accumulation of low-density lipoproteins, particularly the oxidatively modified form, in the blood vessels" ${ }^{\prime 5}$. This concept of interaction between dyslipidemia and RAS activation has been proven in laboratory-based studies. "Clinical trials also suggest that blockade of dyslipidemia and RAS may have a synergistic salutary effect on the outcome of patients with hypertension and/or manifestations of atherosclerosis" ${ }^{5}$. However, little is known about the underlying mechanisms by which lipids interact with RAS in heart failure.

Assessment of lipid profile is used as one of the standard tests to determine cardiovascular disease (CVD) risk. Noteworthy, in the presence of normal lipid profile the possibility of CVD cannot be excluded. It has been demonstrated that when the traditional lipid indicators: triglycerides (TGL), high-density lipoprotein cholesterol (HDL-C), lowdensity lipoprotein cholesterol (LDL-C), and total cholesterol (TC) show normal levels, the lipid indices such as: atherogenic index of plasma (AIP) = $\log [\mathrm{TG} / \mathrm{HDL}]$, the Castelli Risk Index I (CRI-I)= TC/HDL, Castelli Risk Index II (CRI-II)= LDL/HDL and triglyceride index (TGL-index) $=\mathrm{TG} / \mathrm{HDL}$ might be alternatives in assessment of CVD risk ${ }^{6-10}$. According to the current understandings AIP and LDL/HDL ratio may predict ischemic heart disease risk ${ }^{11-14}$, whereas TC/HDL ratio has been reported to be associated with metabolic derangement predictive of cardiovascular risks and related to insulin resistance ${ }^{15,16}$. As for TGL/HDL ratio, it has been reported as a marker of insulin resistance and small LDL ${ }^{17,18}$.

The primary goal of this study was to investigate whether an association between lipid indices AIP, CRI-I, CRI-II and TGL-index and the development of LVH exists in patients with HFmrEF with normal lipid profile. 


\section{PATIENTS AND METHODS}

\section{Inclusion and exclusion study criteria}

Study inclusion criteria: patients with chronic heart failure with mid-range ejection fraction and normal lipid profile. HFmrEF was defined by the criteria of 2016 European Society of Cardiology Guidelines for the diagnosis ${ }^{19}$ and treatment of acute and chronic heart failure: (1) HF symptoms with/without signs; (2) left ventricular ejection fraction determined by echocardiography in the following range (40-49\%); (3) relevant structural heart disese with/or diastolic dysfunction.

-Study exclusion criteria: known autoimmune disease, collagenoses, malignant disease, advanced renal disease (creatinine levels more than $250 \mu \mathrm{mol} / \mathrm{l}$ and hemodialysis), bacterial endocarditis, pulmonary thromboembolism, informed consent refusal. Subjects from the control group were randomly assigned from a family doctor's practice. Healthy volunteers were informed beforehand with the aims and methods of the study and signed informed consent.

\section{Ethics Statement}

The scientific project was approved by the ethics commission of Medical University-Pleven. All the procedures followed were in accordance with the ethical standards of the responsible committee on human experimentation (institutional or regional) and with the Helsinki Declaration of 1975, as revised in 2000. All subjects were informed beforehand with the aims and methods of the study and they signed informed consent.

\section{Subjects}

The examined clinical contingent was from the vicinity of the Pleven University Hospital, Bulgaria. Subjects' sera were taken from experienced staff. The current study included 56 patients with HFmrEF and normal lipid profile, median age 64 (4784 ) and control group of 22 age and sex matched healthy subjects with no family history of diabetes, atherosclerosis or hypertension, median age 58 (51-69).

\section{Hypertension-Mediated Organ Damage (HMOD) Evaluation}

HMOD refers to structural or functional changes in arteries or end organs (heart, blood vessels, brain, eyes, and kidney) caused by an elevated blood pressure (BP), and is a marker of pre-clinical or asymptomatic cardiovascular disease (CVD). To assess presence of heart HMOD patients were inspected by: anamnesis and physical examination for established cardiovascular or premature CVD, 12-lead ECG and transthoracic echocardiography. In order to determine presence of brain HMOD patients were investigated by: anamnesis and physical examination for cerebrovascular damage. To evaluate presence of eyes HMOD patients were examined by: anamnesis and physical examination for ophthalmological damage and fundoscopy. To assess presence of kidney HMOD patients were explored by: anamnesis and physical examination for renal damage, blood creatinine and eGFR. If any HMOD was found at the initial examination, then patient was further consulted with a referring specialist (cardiologist, nephrologist, neurologist, ophthalmologist).

\section{Blood pressure}

Hypertension was defined according to The 2018 ESC/ESH Arterial Hypertension Guidelines ${ }^{20}$ as office systolic BP (SBP) values $\geq 140 \mathrm{mmHg}$ and/or diastolic BP (DBP) values $\geq 90 \mathrm{mmHg}$ via repeated office BP measurements. Arterial blood pressure was measured using a standard anearoid sphygmomanometer, to the nearest $2 \mathrm{mmHg}$, in the dominant arm after at least 10 -min rest in supine position.

\section{Electrocardiography}

Electrocardiography was performed for LVH assessment and the Sokolow-Lyon index, Cornell voltage duration product or Cornell voltage were estimated ${ }^{21}$.

\section{Echocardiography}

To assess the left ventricular ejection fraction, cardiac structure and function parameters, 2D (two-dimensional) transthoracic echocardiography was performed with General Electric (Vivid S5) with 4-MHz transducer. All measurements were obtained according to European Association of Cardiovascular Imaging (EACVI) and The American Society of Echocardiography (ASE) criteria for Cardiac Chamber Quantification by Echocardiography ${ }^{22}$. Using echocardiographic 
Table 1. Clinical data of patients with heart failure with mid-range ejection fraction and healthy controls

\begin{tabular}{|c|c|c|c|}
\hline Clinical data & HFmrEF+LVH & HFmrEF-LVH & Controls \\
\hline Age & $63(47-82)$ & $64(52-84)$ & $58(51-69)$ \\
\hline Gender (M/F) & $18 / 14$ & $14 / 10$ & $12 / 10$ \\
\hline Mean duration $\mathrm{AH}$ (years) & $9.57 \pm 6.63$ & $7.63 \pm 5.26$ & N/A \\
\hline Mean duration HF (years) & $5.6 \pm 2.9$ & $4.89 \pm 1.60$ & N/A \\
\hline $\mathrm{SBP}(\mathrm{mmHg})$ & $151.35 \pm 16.05$ & $139.11 \pm 18.42$ & $118.26 \pm 13.74$ \\
\hline $\mathrm{DBP}(\mathrm{mmHg})$ & $89.05 \pm 10.32$ & $84.41 \pm 11.73$ & $76.4 \pm 8.4$ \\
\hline BMI $\left(\mathrm{kg} / \mathrm{m}^{2}\right)$ & $28.52 \pm 5.99$ & $28.36 \pm 4.96$ & $22.11 \pm 3.27$ \\
\hline Total cholesterol (mmol/l) & $4.99 \pm 1.30$ & $4.79 \pm 0.83$ & $3.99 \pm 0.65$ \\
\hline $\mathrm{HDL}(\mathrm{mmol} / \mathrm{l})$ & $0.87 \pm 0.29$ & $1.16 \pm 0.20$ & $0.96 \pm 0.20$ \\
\hline LDL (mmol/l) & $3.27 \pm 1.17$ & $3.01 \pm 1.07$ & $2.43 \pm 0.64$ \\
\hline Triglycerides (mmol/l) & $1.49 \pm 1.66$ & $1.50 \pm 1.39$ & $1.31 \pm 0.61$ \\
\hline Blood glycose (mmol/l) & $6.00 \pm 0.52$ & $6.11 \pm 0.83$ & N/A \\
\hline Creatinine $(\mu \mathrm{mol} / \mathrm{l})$ & $101.21 \pm 2.87$ & $99.58 \pm 3.69$ & N/A \\
\hline Hypertensive heart damage & $(n=21)$ & - & \\
\hline Hypertensive brain damage & $(n=4)$ & $(n=2)$ & \\
\hline Hypertensive kidney damage & $(n=6)$ & $(n=4)$ & \\
\hline Hypertensive eye damage & $(n=2)$ & $(n=2)$ & \\
\hline Smoking & 21 & 16 & 8 \\
\hline Count & 32 & 24 & 22 \\
\hline
\end{tabular}

Data are presented as mean \pm SD

List of abbreviations in alphabetical order: BMI - Body mass index; DBP - Diastolic blood pressure; HDL - High density lipoprotein cholesterol; $\mathrm{HFmrEF}+\mathrm{LVH}$ - mid-range ejection fraction and left ventricular hypertrophy; HFmrEF-LVH - mid-range ejection fraction without left ventricular hypertrophy; LDL - Low density lipoprotein cholesterol; SBP - Systolic blood pressure; M - male; F - female; AH - arterial hypertension; HF - heart failure

Table 2. Echocardiographic data of all patients with heart failure with mid-range ejection fraction

\begin{tabular}{|l|c|}
\cline { 2 - 2 } \multicolumn{1}{c|}{} & All patients \\
\hline LVEDD & $49.73 \pm 6.64$ \\
\hline LVESD & $36.49 \pm 3.33$ \\
\hline LVEDV & $118.14 \pm 35.9$ \\
\hline LVESV & $61.88 \pm 19.77$ \\
\hline IVS & $12.6 \pm 1.54$ \\
\hline LVPWD & $12.63 \pm 1.52$ \\
\hline EF\% & $47.55 \pm 2.37$ \\
\hline LV mass $(g)$ & $155 \pm 23.58$ \\
\hline LVMI $\left(\mathrm{g} / \mathrm{m}^{2}\right)$ & $45.58 \pm 5.65$ \\
\hline Count & 56 \\
\hline
\end{tabular}

Data are presented as mean \pm SD

List of abbreviations: LVEDD - left ventricular end-diastolic diameter; LVESD - left ventricular end-diastolic systolic diameter; LVEDV - left ventricular end-diastolic volume; LVESV - left ventricular end-systolic volume; IVS - interventricular septal thickness; LVPWD - posterior wall thickness; EF\% - left ventricular ejection fraction; LVM - left ventricular mass; LVMI - left ventricular mass index
Table 3. Echocardiographic data of patients with heart failure with mid-range ejection fraction divided by presence or absence of LVH

\begin{tabular}{|l|c|c|c|}
\cline { 2 - 4 } \multicolumn{1}{c|}{} & HFmrEF+LVH & HFmrEF-LVH & P \\
\hline LVEDD & $52.13 \pm 5.81$ & $45.25 \pm 6.01$ & $0.0004^{*}$ \\
\hline LVESD & $39.44 \pm 4.66$ & $33.69 \pm 3.5$ & $0.0001^{*}$ \\
\hline LVEDV & $132.25 \pm 34.36$ & $91.63 \pm 21.84$ & $0.0001^{*}$ \\
\hline LVESV & $58.22 \pm 14.0$ & $58.22 \pm 14.0$ & $0.0002^{*}$ \\
\hline IVS & $13.38 \pm 1.18$ & $0.94 \pm 0.85$ & $<0.0001^{*}$ \\
\hline LVPWD & $13.41 \pm 1.01$ & $0.95 \pm 1.12$ & $<0.0001^{*}$ \\
\hline EF\% & $47.5 \pm 2.4$ & $47.81 \pm 2.37$ & $p>0.05$ \\
\hline LV mass $(g)$ & $193.96 \pm 28.76$ & $118.67 \pm 19.83$ & $<0.0001^{*}$ \\
\hline LVMI $\left(\mathrm{g} / \mathrm{m}^{2}\right)$ & $54.34 \pm 6.86$ & $36.44 \pm 4.5$ & $<0.0001^{*}$ \\
\hline Count & 32 & 24 & \\
\hline
\end{tabular}

Data are presented as mean $\pm \mathrm{SD},{ }^{*}$ Comparison between groups by ANOVA List of abbreviations: HFmrEF+LVH - mid-range ejection fraction and left ventricular hypertrophy; HFmrEF-LVH - mid-range ejection fraction without left ventricular hypertrophy; LVEDD - left ventricular end-diastolic diameter; LVESD - left ventricular end-diastolic systolic diameter; LVEDV - left ventricular end-diastolic volume; LVESV - left ventricular end-systolic volume; IVS - interventricular septal thickness; LVPWD - posterior wall thickness; EF\% - left ventricular ejection fraction; LVM - left ventricular mass; LVMI - left ventricular mass index 
diagnostic method LVH was defined as: [LV mass weight $>224 \mathrm{~g}$ (men); >162 g (women); LV mass index: men $>50 \mathrm{~g} / \mathrm{m}^{2}$; women $>47 \mathrm{~g} / \mathrm{m}^{2}$ (height in $\mathrm{m})$ ] and LV septal thickness and posterior wall thickness $>0.9 \mathrm{~cm}$ (women); $>1.0 \mathrm{~cm}$ (men).

\section{Laboratory tests}

1. Serum creatinine, blood glucose were determined. Total cholesterol, triglyceride concentrations, HDL were measured by enzyme assay (Boehringer Mannheim, Mannheim, Germany). LDL was calculated via Friedewald formula. Lipid indices were determined by calculation, using the established formulas:

- $A I P=\log [T G / H D L]^{23}$

- Castelli Risk Index I (CRI-I) = TC/HDL ${ }^{24-26}$

- Castelli Risk Index II (CRI-II) = LDL/HDL $24-26$

- $\mathrm{TGL}$ index $=\mathrm{TG} / \mathrm{HDL}^{27}$

2. Mild CKD was detected by eGFR $89-60 \mathrm{~mL} /$ $\mathrm{min} / 1.73 \mathrm{~m}^{2}$ (BSA), moderate CKD was assessed by eGFR > 59-30 mL/min/1.73 $\mathrm{m}^{2}$, while severe CKD by GFR $<29 \mathrm{~mL} / \mathrm{min} / 1.73 \mathrm{~m}^{2}$.

\section{Statistical analyses}

The research data were processed with the computer programs EXCEL (Microsoft Corporation, Redmond, WA) and STATGRAPHICS plus (Manugistics, Rockville, MD) for WINDOWS. All results were described in tables, graphs, numerical values (mean \pm SD, share indicators and correla- tions). The level of significance was determined as $(p<0.05)$. K-W (Kruskal-Wallis)-test was performed in cases with different from normal distribution. Median (M) was used in K-W test, together with the first and third quartile Q1 and Q3; (twenty-fifth and seventy-fifth percentile P25 and 75P). The Pearson test was used for assessing the correlations.

\section{RESULTS}

Forty-one patients were with hypertension mediated organ damage and 15 were without. Patients were divided in two subgroups-subjects with mid-range ejection fraction and left ventricular hypertrophy $(n=32)$, median age 63 (4782 ) years (HFmrEF+LVH); subjects with mid-range ejection fraction without left ventricular hypertrophy $(n=24)$, median age $64 \quad(52-84)$ years (HFmrEF-LVH). Clinical data of patients with HFmrEF and healthy controls are presented in Table 1. Echocardiographic data of all patients with HFmrEF and subgroups with and without LVH are shown in Tables 2 and 3. There was not statistically significant difference between the lipid indices in patients with heart failure with mid-range ejection fraction compared to healthy controls ( $>>0.05$ ) (Fig. 1). HFmrEF+LVH patients showed statistically significantly higher values of atherogenic index of plasma than HFmrEF-LVH patients: $0.16(0.05 \div 0.37)$ vs. $0.04(0.01 \div 0.11) \quad(K W=5.80$;

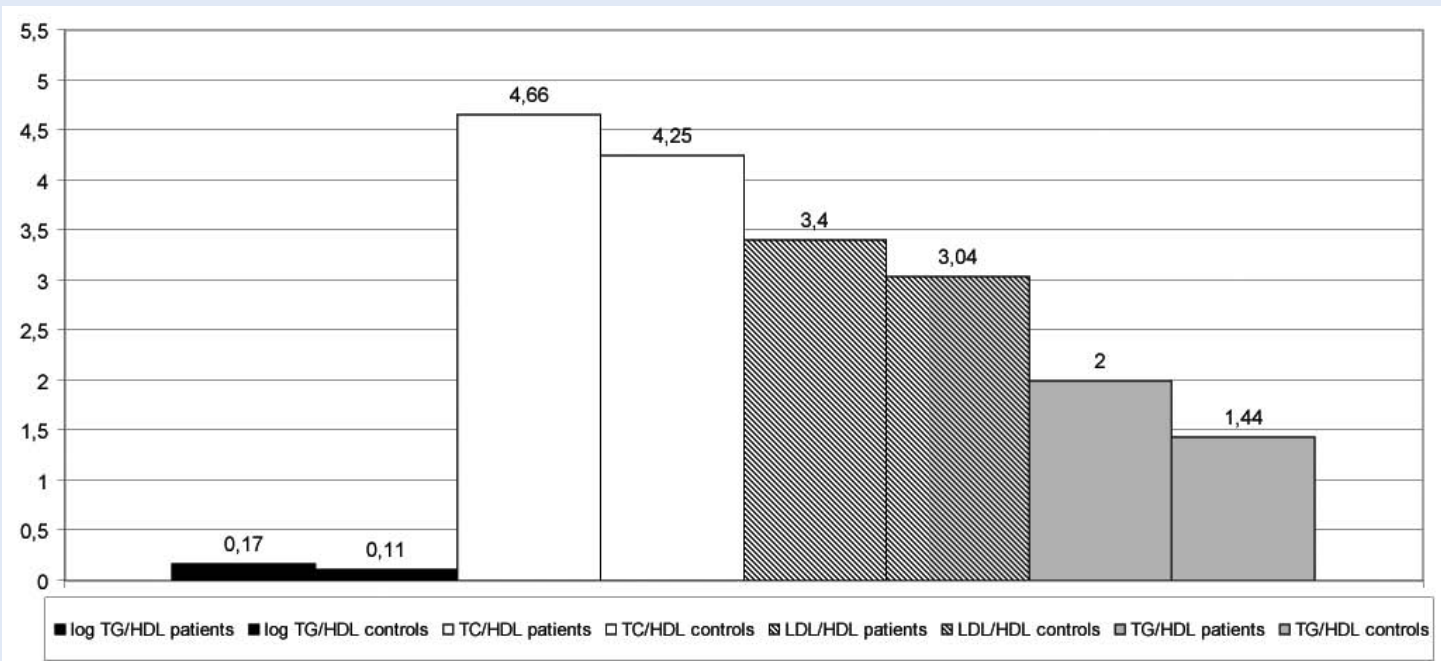

Figure 1. Comparison of lipid indices in patients with heart failure with mid-range ejection fraction vs. healthy controls. $\log \mathrm{TG} / \mathrm{HDL}=$ atherogenic index of plasma, TC - total cholesterol, HDL - high-density lipoprotein cholesterol, LDL - low-density lipoprotein cholesterol, TG - triglycerides. Data are expressed as median. 


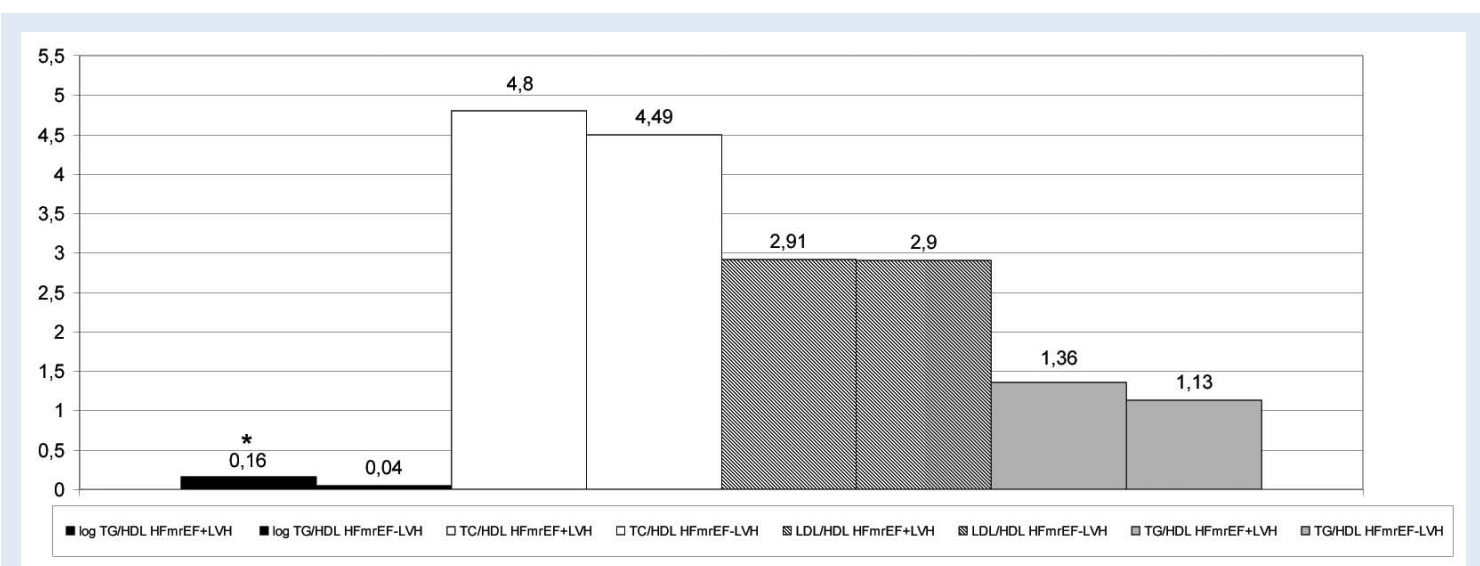

Figure 2. Comparison of lipid indices in patients with HFmrEF with and without LVH.

$\mathrm{HFmrEF}+\mathrm{LVH}$ - mid-range ejection fraction and left ventricular hypertrophy, HFmrEF-LVH- mid-range ejection fraction without left ventricular hypertrophy. log TG/HDL= atherogenic index of plasma, TC- total cholesterol, HDL- high-density lipoprotein cholesterol, LDL- low-density lipoprotein cholesterol, TG- triglycerides. Data are expressed as median; * $p<0.05$.

$\mathrm{p}=0.02$ ) (Fig. 2). TC/HDL, LDL/HDL and TG/HDL values were not significantly higher in HFmrEF+LVH than HFmrEF-LVH patients: 4.8

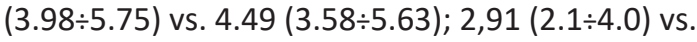
$2.9(2.5 \div 4.25)$ and $1.36(1.11 \div 2.08)$ vs. 1.13 $(0.9 \div 1.53)$, respectively $(p>0.05)$. No significant gender differences between lipid indices were found. Atherogenic index of plasma showed correlation with LVH ( $r=0.45 ; p=0.01)$ and interventricular septum thickness $(r=0.55 ; p=0.002)$.

\section{DISCUSSION}

Current approaches towards LVH in patients with HF provide evidence that it is related to worse prognosis and cardiovascular outcomes. Interestingly, lipid indices in patients with chronic heart failure have not been fully assessed. Studies have involved patients with hypertension, diabetes mellitus, but none of them focused on patients with chronic heart failure with mid-range ejection fraction. Furthermore, there have been almost no reports to date that estimate AIP, CRI-I, CRI-II and TGL-index in patients with HFmrEF, as well their relationship with LVH. As far as we know, the current study is the first to evaluate these indices in such groups of patients.

The interaction between lipids and changes of LV structure and/or function has been demonstrated in several studies. Some of them have investigated the effect of statins on left ventricular remodeling in hypertension and heart failure. For example, Su SF et al. ${ }^{28}$ reported that "addition of pravastatin to antihypertensive treatment led to a greater reduction in left ventricular mass in patients with hypertension and hyperlipidemia". This suggests a link between RAS and hyperlipidemia. In another study, Bauersachs et al. ${ }^{29}$ investigated the effect of statin in left ventricular remodeling after myocardial infarction. This research used an animal model involving rats with heart failure after myocardial infarction. Authors were able to demonstrate that statin therapy improve left ventricular remodeling and function in rats with heart failure. Data from the above mentioned studies suggest that lipoproteins could possibly interplay with angiotensin II and favor the angiotensin II-induced left ventricular remodeling and cardiac fibrosis in hypertension and in heart failure. These processes might occur via angiotensin II-induced mediation. Hence, a cross-talk between dyslipidemia and RAS relative to vascular dynamics is proposed ${ }^{30}$.

It has been reported that the fatty acid composition of serum cholesterol esters mainly reflects dietary fat quality over the previous two weeks ${ }^{31}$ and predicts myocardial infarction ${ }^{32,33}$. Unfortunately, its relationship to LVH has not been investigated. One-sample Mendelian randomization (MR) analysis demonstrated that both LDL cholesterol and triglycerides have a potentially causal association with increased LV mass. According to this study finding, low-density lipoprotein cholesterol and triglycerides may have a causal impact on adverse changes in cardiac 
structure and function, especially in relation to LV mass. "LDL cholesterol and triglycerides appear to be causative of myocardial remodeling by increasing LV mass, suggesting that they influence the development of cardiovascular disease not only by atherosclerosis but also by causing adverse alterations in cardiac structure and function" ${ }^{34}$.

In order to evaluate whether simvastatin administration was associated with regression of cardiac hypertrophy, fibrosis and improvement of LV function, Patel R. et al. used a transgenic rabbit model of human hypertrophic cardiomyopathy. Study represented that "simvastatin induced the regression of hypertrophy and fibrosis, improved cardiac function, and reduced ERK1/2 activity in the beta-myosin heavy chain- $Q$ (403) rabbits" ${ }^{35}$. Considering these results, the following hypothesis arises: whether a reverse LVH effect may be expected if a statin is used in different subjects groups- for example patients with heart failure and/or hypertension. Moreover, previous cross-sectional studies have suggested adverse remodeling changes in association with non-HDL cholesterol and total cholesterol, respectively ${ }^{36,37}$.

Schillaci et al. ${ }^{38}$ revealed an independent relationship of low HDL cholesterol to LV mass in male and female hypertensive patients. In addition, by using proton magnetic resonance spectroscopy Kankaanpää et al. demonstrated accumulation of TG in myocardium of moderately obese subjects. They reported that "free fatty acid levels were a significant predictor of LV mass, whereas myocardial and epicardial fat were more strongly related to LV work and mechanical load"39. Similarly, Kaminagaet al. concluded that hypertrophic cardiomyopathy may be associated with the presence of myocardial fat in the LV with a thickened wall ${ }^{40}$. Furthermore, an autoptic study of human hearts by da Silva RMS et al. in 2017 provided evidence that the fat deposition in the left ventricle constitutes a direct risk of cardiac hypertrophy ${ }^{41}$.

In a large prospective longitudinal cohort study involving 2322 healthy men followed up for 20 years, Sundström et al. reported that dyslipidemia and indices of a low dietary intake of linoleic acid and high intake of saturated andmonounsaturated fats, as well as hypertension and obesity, at age 50 predicted the prevalence of echocardiographic LVH and geometric subtypes. These results also suggest that lipids may play an important role in the origin of $\mathrm{LVH}^{33}$. The effect of serum lipids on LVH and LV diastolic dysfunction was investigated by Horio et al. In their study, the researchers examined 274 patients with treated essential hypertension by echocardiography. The relationship of dyslipidemia, especially low HDL cholesterol to LV hypertrophy and diastolic function was investigated. Authors found that low HDL cholesterol may

There is an association between atherogenic index of plasma and left ventricular hypertrophy in patients with heart failure with mid-range ejection fraction. Determination of atherogenic index of plasma values may be a useful method for monitoring the development and progression of left ventricular hypertrophy in patients with heart failure with mid-range ejection fraction.

unfavorably modify LV structure and diastolic function in patients with treated essential hyperten$\operatorname{sion}^{42}$.

Wang et al. described the influence of nontraditional lipid profiles on left ventricular geometric abnormalities in general Chinese population. The results indicated that "nontraditional lipid profiles were positive determinants of concentricity index and LV wall thickness". The effects on LV mass index were modest, whereas Non-HDL-C correlated independently with concentric LVH. Authors concluded that "nontraditional lipid profiles were responsible for increased risk of concentric LVH, potentially providing enhanced clinical utility at no additional cost, which emphasized the beneficial effect of these markers to supplement and improve CVD risk stratification"43.

Oresegun $\mathrm{OO}$ et al. determined prevalence of dyslipidaemia in hypertensive subjects and its relationship with left ventricular hypertrophy via cross-sectional study involving 120 hypertensive participants with LVH and 60 age and sexmatched hypertensive participants without LVH. Authors found that overall prevalence of dyslipidaemia in participants with LVH was slightly lower than in participants without LVH, but the 
difference was not statistically significant. Investigators reported a positive correlation between echocardiographic left ventricular mass and AIP. Oresegun $\mathrm{OO}$ et al. concluded that there is a high prevalence of dyslipidaemia among hypertensive adults and a positive correlation exists between echocardiographic left ventricular mass and AIP among adult hypertensive subjects ${ }^{44}$.

In a similar research, Kumar $\mathrm{M}$ et al. determined prevalence of dyslipidaemia in hypertensive subjects and its relationship with left ventricular hypertrophy in a cross-sectional comparative study involving 100 hypertensive participants with LVH and 50 age and sex-matched hypertensive participants without LVH. The mean AIP in the hypertensive participants with LVH was higher than in their hypertensive counterparts without LVH, and the difference was statistically significant. Authors concluded that there is a high prevalence of dyslipidaemia among hypertensive adults and a positive correlation between echocardiographic left ventricular mass and AIP among adult hypertensive subjects ${ }^{45}$.

The present study demonstrated two key findings: (1) a statistically significantly higher values of atherogenic index of plasma ( $\log \mathrm{TG} / \mathrm{HDL})$ in HFmrEF+LVH than HFmrEF-LVH patients and (2) a correlation between atherogenic index of plasma and LVH. These results assume a potential link between the high atherogenic risk and LVH in chronic heart failure. Our findings indicated that solely logTG/HDL ratio, but not TG or HDL levels were associated with LVH. Of note, all patients in the current study were with normal traditional lipid profile levels.

Possible explanations could be:

- Current evidence towards VLDLs is that they are major transporters of TG. This proposes potential signaling pathways possibly activated by the VLDL, which could result in neuro-hormonal and metabolic factors overproduction (the described correlation between log TG/HDL ratio and LVH supports that hypothesis).

- Inflammation plays a central role in adverse LV remodeling. It is possible proinflammatory cytokines like tumor necrosis factor alpha (TNF- $\alpha$ ) further to promote adverse cardiac remodelling. The functional relation between angiotensin II and TNF- $\alpha$ has also been reported to cause left ventricular remodelling in hypertensive subjects $^{46,47}$.

- Angll is a major RAS component and plays a key role in hypertension and LVH development via stimulating proinflammatory, profibrotic, vasoconstrictive and remodelling effects ${ }^{48,49}$. Considering the potential interplay between RAS and lipids ${ }^{5}$ suggested by the high logTG/HDL ratio (indirectly VLDL levels and HLD levels) and its correlation with LVH in the current study, we can not exclude possible effects of signalling pathways activated by the VLDL. These processes may result in Angll overproduction and development of left ventricular hypertrophy. Besides the reported lipid indices' determination in the present study, the evaluation of angiotensin II in the same group of subjects was one of the aims of our previous investigations. Thus, we have already measured the serum concentrations of Angll in these subjects. The patients with HFmrEF+LVH showed significantly higher levels of Angll than HFmrEF-LVH and healthy controls Nikolov et al. ${ }^{50,51}$. These results also give arguments supportive for a theory of the lipid interaction with RAS (probably mediated by AngII) and leading to LVH. However, the interplay mechanisms are not known yet.

- All patients in the present investigation were with compensated chronic heart failure treated with optimal therapy, following the appropriate guidelines. This can be one of the possible reasons for lack of statistical difference between AIP values in all patients compared with healthy controls. Therefore, we must consider the possibility that some types of antihypertensive agents may have affected cardiac structure and lipid levels.

- An eventual process of latent lipid depositions in left ventricle is assumed, promoting abnormal changes in LV structure ${ }^{37-39}$. Probably more accurate methods like cardiovascular magnetic resonance or positron emission tomography scan would identify that hypothesis.

There is evidence that the atherogenic index of plasma predicts cardiovascular risk. AIP is calculated by the ratio of logarithm of TGL to HDL levels. AIP values higher than 0.11 are considered as increased CVD risk. The results obtained from the present research suggest an association between 
high AIP values and left ventricular hypertrophy in chronic heart failure with mid-range ejection fraction. It should be considered that the current study was case-control and we assessed the lipid ratios, so the role of causal relationship cannot be commented upon. Although we have not established a direct reason which links events, we report an association between AIP and left ventricular hypertrophy. To the best of our knowledge, our study has provided for the first time evaluation of these lipid indices in subjects with chronic heart failure with mid-range ejection fraction with normal lipid profile. Our data showed that the values of AIP in patients with HFmrEF+LVH were significantly higher than in patients without left ventricular hypertrophy. In addition, a correlation between atherogenic index of plasma and LVH was found. This provides an important data in the explanation of a potential relationship between lipids' turnover and LV structural changes.

\section{Limitations of the study}

The present research had several limitations. Firstly, it was a case-control study and we were not able to perform serial measurements of lipid indices. Secondly, the small sample size and the fact that the control group subjects were younger and in better shape (thinner) than the test groups were also limitations of study design. However, this is the first investigation reporting an association between atherogenic index of plasma and LVH in patients with HFmrEF with normal lipid profile.

\section{CONCLUSIONS}

Our findings showed an association between atherogenic index of plasma and LVH in patients with HFmrEF with normal lipid profile. The exact mechanisms of this relationship are unclear. Larger and longitudinal studies with more sensitive methods are needed to clarify the interrelationships between AIP and changes in left ventricular morphology. They should confirm whether determination of AIP may be used for monitoring the development and progression of left ventricular hypertrophy in heart failure with mid-range ejection fraction.
Funding: This research was funded by "Centre of Scientific Research", Medical University - Pleven, Bulgaria.

Conflicts of Interest: Authors declare no conflicts of interest.

\section{REFERENCES}

1. Levy D, Garrison RJ, Savage DD, Kannel WB, Castelli WP. Prognostic implications of echocardiographically determined left ventricular mass in the Framingham Heart Study. N Engl J Med 1990;322:1561-66.

2. Gradman AH, Alfayoumi F. From left ventricular hypertrophy to congestive heart failure: management of hypertensive heart disease. Prog Cardiovasc Dis 2006;48:326-41.

3. Margonato D, Mazzetti S, De Maria R, Gorini M, lacoviello $\mathrm{M}$, Pietro Maggioni A et al. Heart Failure With Mid-Range Or Recovered Ejection Fraction: Differential Determinants Of Transition. Card Fail Rev 2020;6:28.

4. Albakri A. Heart failure with mid-range ejection fraction A review of clinical status and meta-analysis of clinical management methods. Front Cardiovasc Med 2018; 8:1-2.

5. Van Linthout $S$, Spillmann $F$, Lorenz $M$, Meloni $M$, Jacobs $F$, Egorova $M$ et al. Vascular-protective effects of high-density lipoprotein include the downregulation of the angiotensin II type 1 receptor. Hypertension 2009; 53:682-7.

6. Criqui $\mathrm{MH}$, Golomb BA. Epidemiologic aspects of lipid abnormalities. Am J Med 1998;105:48-57.

7. Akpinar O, Bozkurt A, Acartürk E, Seydaoglu G. A new index (CHOLINDEX) in detecting coronary artery disease risk. Anadolu Kardiyol Derg 2013;13:315-9.

8. Bhardwaj S, Bhattacharjee J, Bhatnagar MK, Tyagi S. Atherogenic index of plasma, Castelli risk index and atherogenic coefficient- new parameters in assessing cardiovascular risk. Int J Pharm Bio Sci 2013;3:359-64.

9. Nwagha UI, Ikekpeazu EJ, Ejezie FE, Neboh EE, Maduka IC. Atherogenic index of plasma as useful predictor of cardiovascular risk among postmenopausal women in Enugu, Nigeria. Afr Health Sci 2010;10:248-52.

10. Dobiásová $M$, Frohlich J, Sedová M, Cheung MC, Brown BG. Cholesterol esterification and atherogenic index of plasma correlate with lipoprote in size and findings on coronary angiography. J Lipid Res 2011;52:566-71.

11. Lemieux I, Lamarche B, Couillard C, Pascot A, Cantin B, Bergeron J et al. Total Cholesterol/HDL cholesterol ratio vs LDL cholesterol/HDL cholesterol ratio as indices of ischaemic heart disease risk in men: the Quebec Cardiovascular Study. Arch Intern Med 2001;161:268592.

12. Cui Y, Blumenthal RS, Flaws JA, Whiteman MK, Langenberg P, Bachorik PS et al. Non-highdensitylipoprotein cholesterol level as a predictor ofcardiovascular disease mortality. Arch Intern Med 2001;161:1413-9.

13. Bittner V, Hardison R, Kelsey SF, Weiner BH, JacobsAK, Sopko G. Non-high-density lipoprotein cholesterol levels predict five-year outcome in the Bypass Angioplasty Revascularization Investigation (BARI). Circulation 2002;106:2537-42. 
14. Ridker PM, Rifai N, Cook NR, Bradwin G, Buring JE. NonHDL cholesterol, apolipoproteins A-I and B100, standard lipid measures, lipid ratios, and CRP as riskfactors for cardiovascular disease in women. JAMA 2005;294:326-33.

15. Ovbiagele B, Saver JL, Fredieu A, Suzuki S, McNair N, Dandekar $\mathrm{A}$ et al. PROTECT: a coordinated stroke treatment program to prevent recurrent thromboembolic events. Neurology 2004;63:1217-22.

16. Smaha LA. The American Heart Association Get with the Guidelines program. Am Heart J 2004;148:46-8.

17. Bianchi C, Penno G, Malloggi L, Barontini R, Corfini M, Giovannitti MG et al. Non-traditional markers of atherosclerosis potentiate the risk of coronaryheart disease in patients with type 2 diabetes andmetabolic syndrome. Nutr Metab Cardiovasc Dis 2008;18:31-8.

18. Sumner AE, Finley KB, Genovese DJ, Criqui MH, Boston $\mathrm{RC}$. Fasting triglyceride and the triglyceride-HDL cholesterol ratio are not markers of insulin resistance in African Americans. Arch Intern Med 2005;165:1395-400.

19. Ponikowski P, Voors AA, Anker SD, Bueno H, Cleland JGF, Coats AJS et al. 2016 ESC Guidelines for the diagnosis and treatment of acute and chronic heart failure: The Task Force for the diagnosis and treatment of acute and chronic heart failure of the European Society of Cardiology (ESC) Developed with the special contribution of the Heart Failure Association (HFA) of the ESC. Eur Heart J 2016;37,2129-2200.

20. Williams B, Mancia G, Spiering W, Rosei EA, Azizi M, Burnier M et al. 2018 ESC/ESH Guidelines for the management of arterial hypertension. Eur Heart J 2018;39: 3021-3104.

21. Lehtonen AO, Puukka P, Varis J, Porthan K, Tikkanen JT, Niemninen MS et al. Prevalence and prognosis of ECG abnormalities in normotensive and hypertensive individuals. J Hypertens 2016;34:959-66.

22. Marwick TH, Gillebert TC, Aurigemma G, Chirinos J, Derumeaux $G$, Galderisi $M$ et al. Recommendations on the use of echocardiography in adult hypertension: a report from the European Association of Cardiovascular Imaging (EACVI) and the American Society of Echocardiography (ASE). Eur Heart J Cardiovasc Imaging 2015;16:577-605.

23. Dobiášová M. Atherogenic index of plasma [log(triglycerides/HDL-cholesterol)]: theoretical and practical implications. Clin Chem 2004;50:1113-5.

24. Stampfer MJ, Sacks FM, Salvini S, Willett WC, Hennekens $\mathrm{CH}$. A prospective study of cholesterol, apolipoproteins, and the risk of myocardial infarction. N Engl J Med 1991;325: 373-81.

25. Ridker PM, Stampfer MJ, Rifai N. Novel risk factors for systemic atherosclerosis: a comparison of C-reactive protein, fibrinogen, homocysteine, lipoprotein(a), and standard cholesterol screening as predictors of peripheral arterial disease. JAMA 2001;285:2481-5.

26. Castelli WP, Abbott RD, McNamara PM. Summary estimates of cholesterol used to predict coronary heart disease. Circulation 1983;67:730-4.

27. Brehm A, Pfeiler G, Pacini G, Vierhapper H, Roden M. Relationship between serum lipoprotein ratios and insulin resistance in obesity. Clin Chem 2004;50:2316-22.

28. Su SF, Hsiao CL, Chu CW, Lee BC, Lee TM. Effects of pravastatin on left ventricular mass in patients with hyperlipidemia and essential hypertension. Am J Cardiol 2000;86:514-8.

29. Bauersachs J, Galuppo P, Fraccarollo D, Christ M, Ertl G. Improvement of left ventricular remodeling and function by hydroxymethylglutaryl coenzyme a reductase inhibition with cerivastatin in rats with heart failure after myocardial infarction. Circulation 2001; 104:982-5.

30. Singh BM, Mehta JL. Interactions Between the ReninAngiotensin System and Dyslipidemia: Relevance in the Therapy of Hypertension and Coronary Heart Disease. Arch Intern Med 2003;163:1296-04.

31. Nikkari T. Serum fatty acids and coronary heart disease in Finnish opulations. Prog Lipid Res 1986;25:437-50.

32. Ohrvall M, Berglund L, Salminen I, Lithell $H$, Aro A, Vessby B. The serum cholesterol ester fatty acid composition but not the serum concentration of alpha tocopherol predicts the development of myocardial infarction in 50-year-old men: 19 years follow-up. Atherosclerosis 1996;127:65-71.

33. Sundström J, Lind L, Vessby B, Andrén B, Aro A, Lithell $H$. Dyslipidemia and an unfavorable fatty acid profile predict left ventricular hypertrophy 20 years later. Circulation 2001;103:836-41.

34. Aung N, Sanghvi MM, Piechnik SK, Neubauer S, Munroe PB, Petersen SE. The Effect of Blood Lipids on the Left Ventricle: A Mendelian Randomization Study. J Am Coll Cardiol 2020;76:2477-88.

35. Patel R, Nagueh SF, Tsybouleva N, Abdellatif M, Lutucuta $\mathrm{S}$, Kopelen $\mathrm{HA}$ et al. Simvastatin induces regression of cardiac hypertrophy and fibrosis and improves cardiac function in a transgenic rabbit model of human hypertrophic cardiomyopathy. Circulation 2001;104:31724.

36. Schillaci G, Vaudo G, Reboldi G, Verdecchia P, Lupattelli G, Pasqualini L et al. High-density lipoprotein cholesterol andleft ventricular hypertrophy in essential hypertension. J Hypertens 2001;19:2265-70.

37. Celentano A, Crivaro M, Roman MJ, Pietropaolo I, Greco R, Pauciullo $P$ et al. Left ventricular geometry and arterial function in hypercholesterolemia. Nutr Metab Cardiovasc Dis 2001;11:312-9.

38. Verdecchia P, Schillaci G, Borgioni C, Ciucci A, Battistelli $M$, Bartoccini $C$ et al. Adverse prognostic significance of concentric remodeling of the left ventricle in hypertensive patients with normal left ventricular mass. J Am Coll Cardiol 1995;25:871-8.

39. Kankaanpää M, Lehto H-R, Pärkkä JP, Komu M, Viljanen A, Ferrannini $E$ et al. Myocardial triglyceride content and epicardial fat mass in human obesity: relationship to left ventricular function and serum free fatty acid levels. J Clin Endocrinol Metab 2006;91:4689-95.

40. Kaminaga T, Naitou H, Hamada S, Takamiya M. Detection of myocardial fatty components with ultrafast CT. Nihon Igaku Hoshasen Gakkai Zasshi 1993;53:28-34.

41. da Silva RMS, de Mello RJV. Fat deposition in the left ventricle: descriptive and observacional study in autopsy. Lipids Health Dis 2017;16:86.

42. Horio T, Miyazato J, Kamide K, Takiuchi S, Kawano Y. Influence of low high-density lipoprotein cholesterol on left ventricular hypertrophy and diastolic function in essential hypertension. Am J Hypertens 2003;16:938-44. 
43. Wang H, Li Z, Guo X, Chen Y, Chang Y, Chen S et al. The impact of nontraditional lipid profiles on left ventricular geometric abnormalities in general Chinese population. BMC Cardiovasc Disord 2018;18:88.

44. Oresegun OO, Ogah OS, Familoni OB, Akinpelu A. Correlation between echocardiographic left ventricular mass and atherogenic index of plasma in adult hypertensive subjects in Olabisi Onabanjo university teaching hospital, Sagamu. Int J Adv Med 2020;7:1460-67.

45. Kumar M, Singh DP. Correlation between echocardiographic left ventricular mass and atherogenic index of plasma in hypertensive adult patients. IJHCR 2021;4: 207-13.

46. Sriramula S, Francis J. Tumor necrosis factor - Alpha is essential for angiotensin II-induced ventricular remodeling: Role for oxidative stress. PloS One. 2015;10:8372.

47. Sivasubramanian $\mathrm{N}$, Coker ML, Kurrelmeyer KM, MacLellan WR, DeMayo FJ, Spinale FG et al. Left ventricular remodeling in transgenic mice with cardiac restricted overexpression of tumor necrosis factor. Circulation 2001;104:826-31.

48. Dahlöf B. Left ventricular hypertrophy and angiotensin II antagonists. Am J Hypertens 2001;14:174-82.

49. Cowan BR, Young AA. Left ventricular hypertrophy and renin-angiotensin system blockade. Curr Hypertens Rep 2009;11:167-72.

50. Nikolov AG, Tzekova ML, Kostov KM, Blazhev AB. Association between serum matrix metalloproteinase-12/ angiotensin II profile and left ventricular hypertrophy in patients with heart failure. Arch Balk Med Union 2020;55:233-42.

51. Nikolov A, Tzekova M, Kostov K, Blazhev A, Popovski N. Association Between Timp-3/Angiotensin li Profile and Cardiac Remodeling in Patients with Essential Hypertension and Heart Failure with Mid-Range Ejection Fraction. A J Biomed Sci Res 2019;4:28-31 